\section{Commentary: A problem with the anterior mitral leaflet?}

\author{
Marc Gillinov, MD, Daniel J. P. Burns, MD, MPhil, \\ and Per Wierup, MD, PhD
}

Mitral valve repair is superior to mitral valve replacement in patients with degenerative mitral valve disease. Available data comparing repair with replacement support this statement, and few would disagree. ${ }^{1,2}$ Because the majority of patients with degenerative disease have posterior leaflet prolapse, most of the data supporting the benefits of mitral valve repair are based on the results of posterior leaflet/chordal repair. In this issue of the Journal, Brescia and colleagues ${ }^{3}$ from the University of Michigan present data to support mitral valve repair in those with anterior (or bileaflet) prolapse, as well.

Comparing propensity-matched patients who underwent anterior leaflet repair with those who had posterior leaflet repair, Brescia and colleagues found no difference in residual mitral regurgitation, survival, or freedom from reoperation. At 15 years' follow-up, mitral valve reoperation occurred in $7.5 \%$ of those with anterior leaflet prolapse and in $4.9 \%$ of those with posterior leaflet prolapse; these figures were not statistically different. Based on these excellent results, the authors concluded that surgeons should approach anterior leaflet prolapse as they do posterior leaflet prolapse; to wit, surgeons should repair the valve.

Despite the excellent results reported by Brescia and colleagues, surgeons regard anterior leaflet repair as a particular challenge that yields uncertain results. Why do surgeons perceive a problem with the anterior leaflet? Several factors explain this perspective. Isolated anterior leaflet prolapse is far less common than posterior leaflet prolapse, meaning that surgeons have less experience with such valves. Compounding this, anterior leaflet repair is traditionally more challenging than posterior leaflet repair. When creating

\footnotetext{
From the Heart and Vascular Institute, Cleveland Clinic, Cleveland, Ohio. Disclosures: Dr Gillinov serves as a consultant to Edwards Lifesciences, Medtronic,

CryoLife, Abbott, and ClearFlow. Dr Wierup serves as a consultant to Edwards Lifescience, Medtronic, and CryoLife. Dr Burns serves as a consultant to Medtronic.

Received for publication Dec 6, 2019; revisions received Dec 6, 2019; accepted for publication Dec 7, 2019; available ahead of print Jan 3, 2020.

Address for reprints: Marc Gillinov, MD, Department of Thoracic and Cardiovascular Surgery, Cleveland Clinic/Desk J4-1, 9500 Euclid Ave, Cleveland, OH 44195 (E-mail: gillinom@ccf.org).

J Thorac Cardiovasc Surg 2021;162:1097-8

$0022-5223 / \$ 36.00$

Copyright (c) 2019 by The American Association for Thoracic Surgery

https://doi.org/10.1016/j.jtcvs.2019.12.031
}

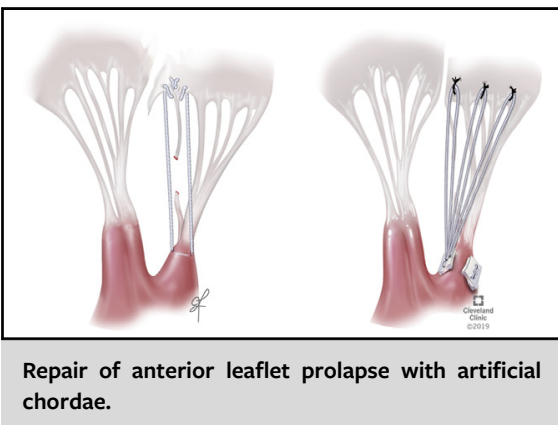

CENTRAL MESSAGE

Mitral valve repair is the procedure of choice for all patients with mitral valve prolapse.

neochordae, determination of chordal length can be difficult. In addition, many patients with isolated anterior leaflet prolapse have diminutive posterior leaflets, rendering it difficult to achieve good leaflet coaptation. Given these surgical challenges and the general perception that anterior repairs have limited durability, some surgeons may favor replacement in these patients.

Although Brescia and colleagues do not provide their repair rates in patients with anterior leaflet prolapse, we can presume that they are quite high in their center (ie, $>90 \%$ across all subsets of prolapse). Their excellent intraoperative and long-term results confirm that repair of anterior prolapse is both feasible and advisable in experienced surgical hands. This supports early referral of all patients with severe mitral regurgitation caused by degenerative disease, regardless of the site of prolapse. After a successful repair, the majority of patients will never need mitral valve surgery again; in addition, they experience low rates of valve-related morbidity. ${ }^{4}$ At this point, experienced surgeons should aim to repair virtually all degenerative valves and should have little problem with the anterior mitral leaflet.

\section{References}

1. Gillinov AM, Blackstone EH, Nowicki ER, Slisatkorn W, Al-Dossari G Johnston DR, et al. Valve repair versus valve replacement for degenerative mitral valve disease. J Thorac Cardiovasc Surg. 2008;138:885-93.

2. Anyanwu AC, Bridgewater B, Adams DH. The lottery of mitral valve repair surgery. Heart. 2010;05:1964-7.

3. Brescia AA, Watt TMF, Rosenbloom LM, Murray SL, Wu X, Romano MA, et al Anterior versus posterior leaflet mitral valve repair: a propensity-matched analysis. J Thorac Cardiovasc Surg. 2021;162:1087-96.e3. 
4. David TE, David CM, Tsang W, Lafreniere-Roula M, Manlhiot C. Long-term results of mitral valve repair for regurgitation due to leaflet prolapse. J Am Coll Cardiol. 2019;74:1044-53.
5. Suri RM, Schaff HV, Dearani JA, Sundt TM, Dalcy RC, Mullany CJ, et al. Survival advantage and improved durability of mitral repair for leaflet prolapse subsets in the current era. Ann Thorac Surg. 2006;82:819-26.
See Article page 1087.

\section{Commentary: In the hands of the experienced, do not fear anterior leaflet pathology}

\author{
Makoto Mori, MD, and Arnar Geirsson, MD
}

With the rapid advancement of transcatheter alternatives to surgical approaches, the surgical community bears the responsibility of optimizing surgical outcomes to provide a fair benchmark against which novel, less-invasive approaches can be compared. Mitral valve repair is one of such operations that has a significant margin for advancement, both via system-level strategies for volume regionalization ${ }^{1}$ and technical-level improvement to optimize the outcomes inherent to the operation itself.

Brescia and colleagues ${ }^{2}$ address the latter aspect in this study by demonstrating that repair of anterior leaflet pathologies, which are repaired less frequently compared with posterior pathologies, may achieve excellent outcomes. In their single-center series, authors reported that the survival and freedom from reoperation were not significantly different between isolated anterior or bileaflet repair versus posterior leaflet repair. The finding is thought-provoking, because anterior leaflet pathology has historically suffered from lower rates of repair, likely owing to existing evidence suggesting that they are less durable. ${ }^{3}$ The report is an encouragement to not discard the repair option solely based on the presence of an anterior leaflet pathology.

The excellent outcomes should be contextualized to the fact that the operations were performed in a highly

\footnotetext{
From the Section of Cardiac Surgery, Yale University School of Medicine, New Haven, Conn.

Disclosures: Authors have nothing to disclose with regard to commercial support.

Received for publication Dec 1, 2019; revisions received Dec 1, 2019; accepted for publication Dec 2, 2019; available ahead of print Dec 17, 2019.

Address for reprints: Arnar Geirsson, MD, Section of Cardiac Surgery, Yale School of Medicine, BB204, 330 Cedar St, P.O. Box 208039, New Haven, CT 06510 (E-mail: arnar.geirsson@yale.edu).

J Thorac Cardiovasc Surg 2021;162:1098-9

$0022-5223 / \$ 36.00$

Copyright (c) 2019 by The American Association for Thoracic Surgery

https://doi.org/10.1016/j.jtcvs.2019.12.005
}

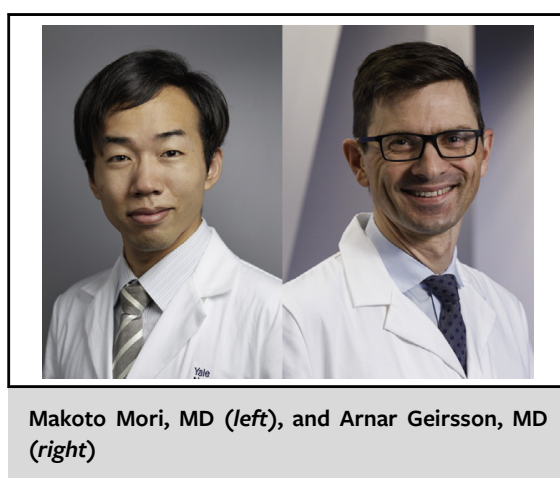

CENTRAL MESSAGE

In experienced hands, anterior

leaflet pathology may be repaired

effectively and safely. The presence

of an anterior leaflet pathology

alone should not limit repair op-

tions in a specialized setting.

specialized setting, with one surgeon operating on the majority $(85.3 \%)$ of this series. Presumably, anterior leaflet repair was performed at an even greater proportion by this operator. Therefore, this report demonstrates what can be achieved in a highly specialized condition, rather than widely generalizable outcomes of anterior versus posterior leaflet repair. Technical complexity of anterior repair would suggest that the 25 repairs/year surgeon volume threshold reported previously ${ }^{4}$ is likely greater when specifically considering anterior leaflet repair.

Caution must be exercised in interpreting the reported nonsignificant difference in the risk of reoperation, as David and colleagues ${ }^{5}$ demonstrated in a single-surgeon series that isolated anterior leaflet prolapse was a significant predictor of recurrent mitral regurgitation and reoperation during the median follow-up of 10 years. ${ }^{5}$ This may be in line with the competing risk analysis by the authors that also showed a nonsignificant but a greater cumulative incidence of reoperation in the anterior repair group $(7.5 \%$ vs $4.9 \%){ }^{2}$ Regardless, repair with an increased risk of reoperation 